\title{
Time management as an important component of successful business activities
}

\author{
N. Skryhun ${ }^{1}$, S. Nyzhnyk ${ }^{2}$ \\ ${ }^{1,2}$ National University of Food Technologies, Kyiv, Ukraine
}

\begin{abstract}
The article examines the main aspects of using time management in enterprise's business practices to effectively use work and personal time. Defined the basic principles of time management and main problems of inefficient use of working time. Suggested the basic techniques of time management as practical tools for improving efficiency time.

Keywords: time management, principles of time management, time, efficiency.
\end{abstract}

\section{Introduction}

In today's tough and frenzied business realities the major human problem is the lack of time. The main problems of modern man are the inability to rationally and efficiently using the most precious resource - time. Everyone at least once faced the problem of lack of time on the main aspects of life, which is due to inability to effectively manage your own time. Time is a unique, most valuable human resource that is limited and short-lived for the person and society as a whole. Everyone can efficiently use this resource in order to convert it to the values of life.

International company «Chipin \& Partner» conducted a study which showed that every year people wasting about 78 days a year in vain, as personal and work time [5, p. 467]. The problem of irrational use of time is one of the biggest challenges of the XXI century. That is why the question of time management research is one of the main tasks of modern managers in order to effectively organize the work of the team and obtain maximum efficiency. The rational use of time is the key to successful work of each employee and achievement of all set goals.

\section{The results}

The issues of studying the rational and effective use of time is devoted to the work of such outstanding domestic scientists in the field of management, marketing, economics and psychology, as O. Havrylova, T. Halaida, V. Hupalov, V. Yevdokymov, H. Yevtushenko, S. Ivanytska, V. Kolpakov, T. Lazorenko, H. Maksymenko, E. Merzliakova, V. Rastymeshyn, V. Usov and others.

Scientific works of prominent foreign scientists, have gained wide popularity, in particular: K. Bischoff, P. Doyle, P. Drucker, L. Seiwert, J. Kennedy, A. Lakein, S. Covey, H. Pletsan, S. Prentice, B. Santo, B. Tracy, S. Ward, H. Fayol and others.

However, despite the large number of theoretical developments in the field of time management, the concepts of time management as a mechanism for improving the organization of the working space of employees are understudied. Also, the main subject of controversy among scientists is the becoming of time management as an independent discipline in the field of management.

Time Management is a set of specific methods and principles of time management in order to fulfill the tasks, events and projects [4].

There are four basic principles of time management: working with goals, setting priorities, awareness in planning tools and developing habits (Fig. 1).

Working with defining goals person should understand that they have to be realistic, specific, measurable and have a clearly defined deadline. The ability to set priorities is a core component of time management, as not every goal is urgent and most important. Without prioritization, the efficient use of time cannot be achieved. 


\section{Goal setting}

\section{Setting priorities}

\section{Awareness in planning tools}

\section{Developing habits}

Fig.1. The core principles of time management [2, p. 60]

There is quite a wide range of planning tools, everyone should be able to choose the most convenient and effective tool for themselves. Today there are various planners, notebooks, diaries, calendars, templates to help plan your day.

It is important to identify the main benefits of time management:

* Quickly and effectively achieve the goals set based on their daily solution and delegation of nonessential tasks;

* Allows to clearly identify the top priorities that will allow using time rationally;

* Operationally adjusting the action plan develops a flexible attitude to any changes in the workflow;

* Effective time allocation skills allow effective use of personal time in everyday life [5, p. 469].

To determine the need for time management among employees, a timing of personal time should be conducted to help identify weaknesses and gaps in the work of each worker. Timing should be performed for several days or weeks to determine the causes of lack of time. After the analysis should identify the strengths and weaknesses of the employee if certain events were not related to business processes, should be done conduct work for their exclusion.

The main causes waste of ime at work are:

\# Non-working telephone calls;

* Poorly organized process of communication between employees of the company;

* Problems with working appliances (computers, tablets, phones);

* Sharp change of tasks from senior management or colleagues;

* Lack of organizational planning in the company;

* Regular coffee breaks or smoking [2, p. 61].

There are two types of time-management, such as personal and corporate time-management.

Personal time management is a combination of different techniques and technologies of workflow organization that an employee creates to meet his or her own goals, to avoid wasting time.

Corporate time management is the organization of efficient use of time of all employees of the company, which helps to use the time of each of them effectively.

Today, there are many techniques that teach how to effectively use a person's most valuable resource - time. Each of the techniques has its own features and certain differences, we will consider 3 basic methods, namely: the Pareto principle, the method of accelerated analysis on the principle of the Eisenhower, the ALPEN methods.

The Pareto principle is widely known in the modern world, it is used not only in time management, but also in many spheres of life. This principle states that only 20 percent of applied effort will help bring 80 percent of the expected results, that is, defining 20 percent of cases is determining the top priorities [1, p. 289]. 
The method of accelerated analysis on the principle of the Eisenhower is the most popular among executives, it launched by US President Dwight David Eisenhower. The peculiarity of the method is determined in the defining importance of the tasks, thanks to the criteria: urgent, not urgent, important and not important. Through this method combines two main criteria, namely, the «importance» and «urgency» that allow determining and improving the efficiency of human activity by identifying priority tasks.

The ALPEN methods were also invented by an American president - John Kennedy allowing you to define a plan for the day, week, or year. Its peculiarity is that this method allows reserving a certain part of the day for the most important tasks. This method divides the main case into 5 spectra: $\mathrm{A}$ - the most important cases, $\mathrm{L}$ - the cases that need to be done, $\mathrm{P}$ - would be good to do but will not bring significant changes, $\mathrm{E}$ - the cases that can be delegated, $\mathrm{N}$ - the cases that should be removed from daily schedule [3, p. 5-6].

There are many other methods of time management, for example:

* The 6P Rule - prior proper planning prevents poor performance;

* The Pomodoro Technique - division of work into 25-minute intervals;

* Franklin Covey system - the definition of long-term life goals and ways to achieve them.

Implementation of these methods in the company will have a positive impact on the organization of work processes within the enterprise, but it should be noted that there is no single universal system that will help once and for all to establish time management. All the above methods, as well as many other techniques should be applied, combined and selected in the combination with techniques and principles that will fit you personally, or your employees to ensure efficiently use of working and personal time.

\section{Conclusions}

Time management is one of the most important and urgent techniques that managers should use among company employees for time management. Working to improve productivity and the rational use of time resource requires setup of management in the enterprise. The development of an enterprise depends directly on how employees plan and organize their work activities. The manager should be able to plan the working hours of each employee, including his or her own, focusing on key and strategic tasks, that will allow you to complete the tasks as quickly and efficiently as possible and to minimize time for routine cases. In order to effectively implement time management for a business, one must adhere to all its principles, use various techniques, combine them to determine the best method for each case, and take into account all the difficulties that may arise in the process.

Methods of time management are effective tools that help efficiently organize your own time and the time of each of the employees to obtain maximum results.

\section{References}

[1] Ivanytska S. Implementation of the European methods of time management in Ukraine // S. Ivanytska, T. Halaida, R. Tolochii // Global and National Problems of Economy. - 2018. № 21. - P. 288-292.

[2] Kalinichenko L. Features of implementation of time management at enterprise / L. Kalinichenko, A. Gavrilova // Young Scientist. - 2017. № 4.4 (44.4). - P. 60-63.

[3] Masliukivska A. The importance of time management for increasing of personal effectiveness / A. Masliukivska // Young Scientist. - 2018. № 11 (63). - P. 467-471.

[4] Prychepa I. Time Management as a powerful tool of a successful manager's effective time in current circumstances // I. Prychepa, I. Solomoniuk, T. Lesko // Efektyvna ekonomika. - 2018. № 12. - P. 1-10.

[5] Time management [Electronic resource] - Access mode: http://bit.do/fnjEw 